\title{
Experimental modeling of silicate-based geothermal deposits
}

\author{
Aslı Çelik ${ }^{\mathrm{a}}$, Gökhan Topçu ${ }^{\mathrm{a}}$, Alper Baba ${ }^{\mathrm{b}}$, Yasar Akdogan ${ }^{\mathrm{a}}$, Ufuk Şentürk ${ }^{\mathrm{a}}$, Mustafa M. Demir ${ }^{\mathrm{a}, *}$ \\ a Department of Materials Science and Engineering, Izmir Institute of Technology, 35430, Gülbahçe, Urla, İzmir, Turkey \\ b Department of Civil Engineering, Izmir Institute of Technology, 35430, Gülbahçe, Urla, İzmir, Turkey
}

\section{A R T I C L E I N F O}

\section{Keywords:}

Scaling

Metal silicates

Synthesis of scaling

Tuzla geothermal field (TGF)

\begin{abstract}
A B S T R A C T
Scaling by metal silicates represents a major obstacle for geothermal systems. A composition that enables the fabrication of artificial deposits is necessary for the rapid testing of potential inhibitors. In this work, artificial deposits were synthesized by employing experimental conditions similar to those in the Tuzla Geothermal Field in Turkey. Although refluxing enabled the formation of a precipitate that was similar to naturally formed deposits in color and texture, their elemental composition and morphology showed a mismatch. An autoclave enabled the production of a precipitate that more closely resembled naturally formed deposits in color, texture, elemental composition, and structure.
\end{abstract}

\section{Introduction}

Geothermal energy is a renewable and sustainable energy source. However, the deposition of scale such as silicates and calcite is one of the main handicaps in many geothermal systems, such as the Tuzla Geothermal Power Plant (TGPP), which is located $5 \mathrm{~km}$ from the Aegean Sea and $80 \mathrm{~km}$ south of the city of Çanakkale, near the ancient city of Aleksandra Troia in northwestern Turkey (Fig. 1). The TGPP has an installed power generation capacity of 7.5 MWe and an annual energy production capacity of $51 \mathrm{GWh}$ and is a closed-cycle system. Significant amounts of seawater enter the fault system such that the water is saturated with atmospheric oxygen. Moreover, the power plant experiences stoppages five times per year, and the system is opened for cleaning and maintenance during this process. Therefore, the system is not free from oxygen.

Scaling problems substantially reduce the efficiency of geothermal power plants and cause financial losses (Baba et al., 2015; Demir et al., 2014). The deposition of scale and related phenomena are considered to be major constraints on the improvement of geothermal energy. Among the different minerals liable to be deposited, silica is a common component and is difficult to remove. Silica precipitates in many different forms in nature (e.g., quartz, tridymite, cristobalite, amorphous silica, etc.) (Ehrlich et al., 2010; Ghouil et al., 2015). Although quartz is mainly observed in nature, extensive deposits of amorphous silica are found to have formed in the Tuzla Geothermal Field (TGF). Amorphous silica precipitates in the form of metal silicate deposits that contain iron and magnesium ions, which are very hard and dense and are difficult to remove from geothermal systems.
The modification of $\mathrm{pH}$ using organic acids appears to provide the best short-term remedy. However, corrosion remains a potential risk to the long-term sustainability of geothermal plants. Attempts have been made in the literature to screen potential organic inhibitors to minimize scaling by metal silicates (Demadis et al., 2012, 2007; Demadis and Neofotistou, 2004; Gallup, 1997, 1998, 2002).

The association of silicate solutions with metal salts has been documented in the literature. Saishu et al. (2013), for instance, examined the effect of a mixture of $\mathrm{Na}^{+}$and $\mathrm{Al}^{3+}$ on the morphology and precipitation rates of silica deposits. The experiments were performed with a constant $\mathrm{Na} / \mathrm{Al}$ ratio of 1.48 and increasing $\mathrm{Al}^{3+}$ concentrations from 0 to $6.7 \mathrm{ppm}$. According to the results, the precipitation rate and the amount of silica precipitated increased with increases in the concentration of $\mathrm{Al}^{3+}$ and $\mathrm{Na}^{+}$. These ions might promote the formation of Na-Al-Si complexes in solution. Moreover, with increases in the amount of these ions the morphology of the precipitates was found to be modified. Although at low $\mathrm{Al}^{3+}$ concentrations amorphous silica was formed, at higher concentrations of $\mathrm{Al}^{3+}$ the amorphous structure was transformed into quartz. This result was attributed to a reduction in the energy barrier required for the nucleation of quartz to occur. In another study, Icopini et al. (2005) investigated the effects of various parameters, such as ionic strength, $\mathrm{pH}$, and different initial concentrations of silica, on the rate of oligomerization of silica. The ionic strengths of all solutions were obtained using a mixture of $\mathrm{Na}^{+}, \mathrm{K}^{+}, \mathrm{Ca}^{2+}, \mathrm{Cl}^{-}$, and $\mathrm{HCO}_{3}{ }^{-}$solutions. Test experiments were carried out at ionic strengths of 0.01 and 0.24 molal (m), pH values ranging from 3 to 11, and initial concentrations of silica of 250, 750, and $1250 \mathrm{ppm}$. The results showed that silica

\footnotetext{
* Corresponding author.

E-mail address: mdemir@iyte.edu.tr (M.M. Demir).
} 


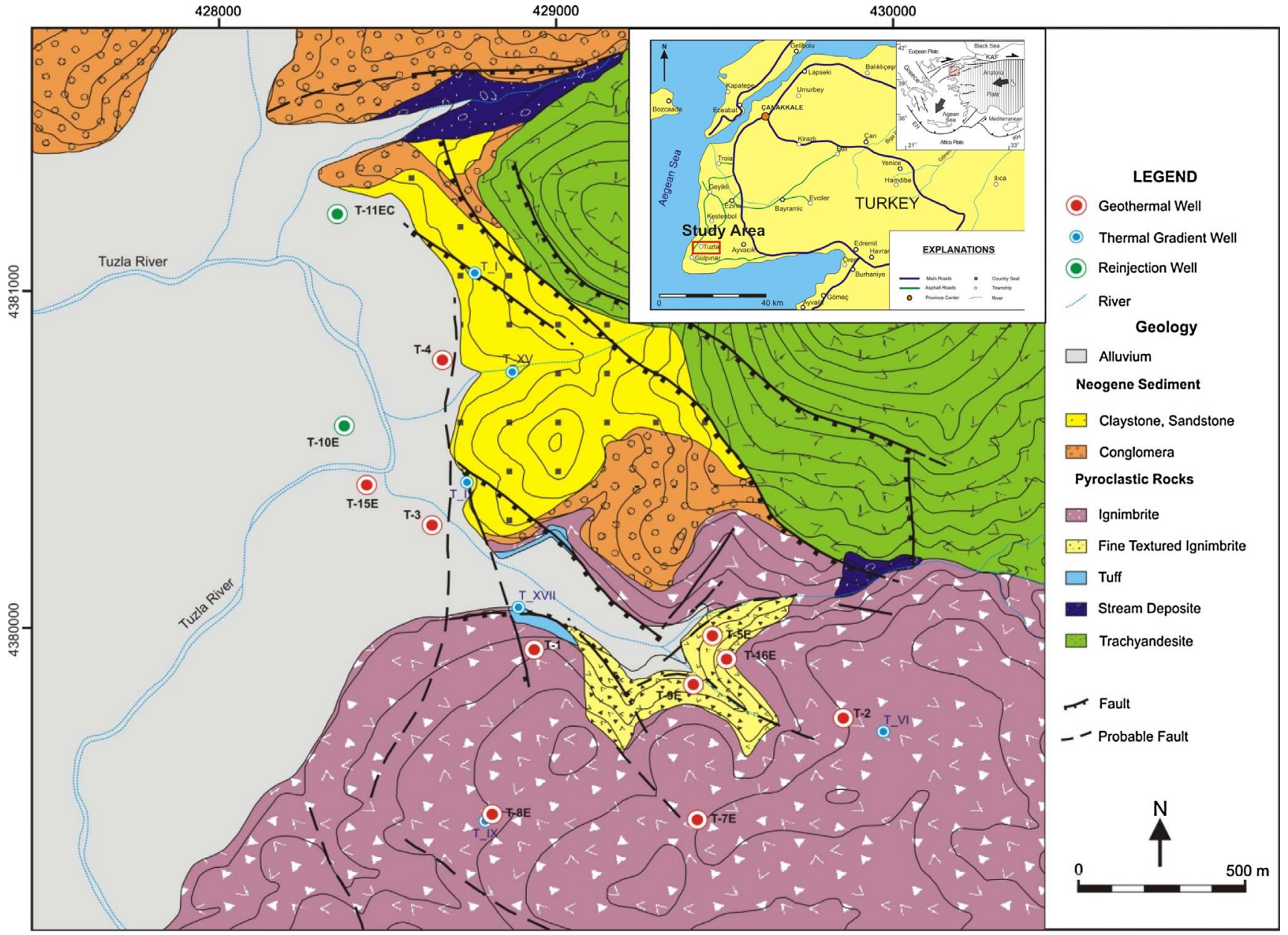

Fig. 1. Location and geological map of study area (WES JEC, 2006; Baba et al., 2015).

nanocolloids were stabilized at low $\mathrm{pH}$ and low ionic strengths but became unstable when the solution $\mathrm{pH}$ was near neutral and at higher ionic strengths and higher initial silica concentrations. The rate of oligomerization of silica was higher by six orders of magnitude in solutions with high ionic strengths than in those with low ionic strengths. Moreover, the rate increased with an increase in the initial concentration of silica. Chen and Marshall (1982) stated that $\mathrm{Na}_{2} \mathrm{SO}_{4}$, $\mathrm{NaCl}, \mathrm{MgSO}_{4}$, and $\mathrm{MgCl}_{2}$ affected the concentration of dissolved silica. Increases in the salt concentration increased the amount of silica precipitated. In addition, the effect of temperature on scaling by silicates was examined, where the experiments were conducted at constant salt concentrations. The results showed that the solubility of silica increased with an increase in temperature. In addition, the effects of added salts and temperature were found to change the structure of the precipitate, which underwent a transformation from amorphous silica to cristobalite or quartz. Gallup et al. (2003) studied the desilication of geothermal water systems to obtain more commercially valuable minerals. The experiments were performed at 90 and $130{ }^{\circ} \mathrm{C}$. Except for $\mathrm{Mg}^{2+}$, other cations reacted with silica to give poorly crystalline metal-rich silicates and co-precipitated as metal carbonates at $90{ }^{\circ} \mathrm{C}$. Raising the temperature to $130{ }^{\circ} \mathrm{C}$ resulted in an increase in the crystalline content of the precipitates, which suggested the formation of more commercially valuable minerals. The results of desilication tests showed that the most effective desilicating agents were $\mathrm{Mn}^{2+}$ and $\mathrm{Fe}^{2+}$. Silica precipitated rapidly with the use of these cations, and a combination of $\mathrm{Mg}^{2+}$ and $\mathrm{Fe}^{2+}$ in solution reacted with silica to give saponite-type precipitates. Brown (2011) examined the thermodynamics and kinetics of scaling by silica. His group performed test experiments on scaling by silica using $\mathrm{NaCl}$ solutions. As the super- saturation index increased, the rate of precipitation of silica also increased. This result was explained by a reduction in the electrostatic attraction between $\mathrm{Na}^{+}$and monosilicic acid. Silica colloids in dilute solutions were very stable and had negative surface charges that prevented the agglomeration of silica particles. If the concentration of the solution reached supersaturation, cations surrounded the negatively charged silica particles, with the results that cations in saturated solutions and silica particles came together to form metal silicate precipitates, negatively charged silica particles approached closer to each other, and larger silica colloids formed.

A methodology for testing the performance of potential inhibitors in laboratory conditions is needed. In this study, synthetic precipitates were produced that had similar compositions and morphologies to those of the deposits collected in the vaporizer of the TGPP. Synthetic brine consisting of Cl-rich salts of the common metal ions $\mathrm{Fe}^{2+}, \mathrm{Mg}^{2+}$, and $\mathrm{Ca}^{2+}$ in the presence of Na silicate was prepared and reacted at high temperatures. Two types of apparatus (reflux and autoclave) were employed for the fabrication of metal deposits. Refluxing is a technique commonly used in chemistry laboratories and can be used as a screening technique for potential inhibitors. On the other hand, an autoclave is a more specialized apparatus in which it is possible to increase and control pressure, $\mathrm{pH}$, and temperature during the synthesis of artificial deposits. The formation of deposits in the autoclave reactor was found to be close to the field conditions, which was a prerequisite for screening potential inhibitors of scaling by metal silicates. The resulting deposits were characterized in terms of elemental composition, morphology, crystal structure, and structural formation. The experimental conditions were adjusted to enable the fabrication of deposits of which the features closely resembled those of naturally observed deposits, to 
(a)
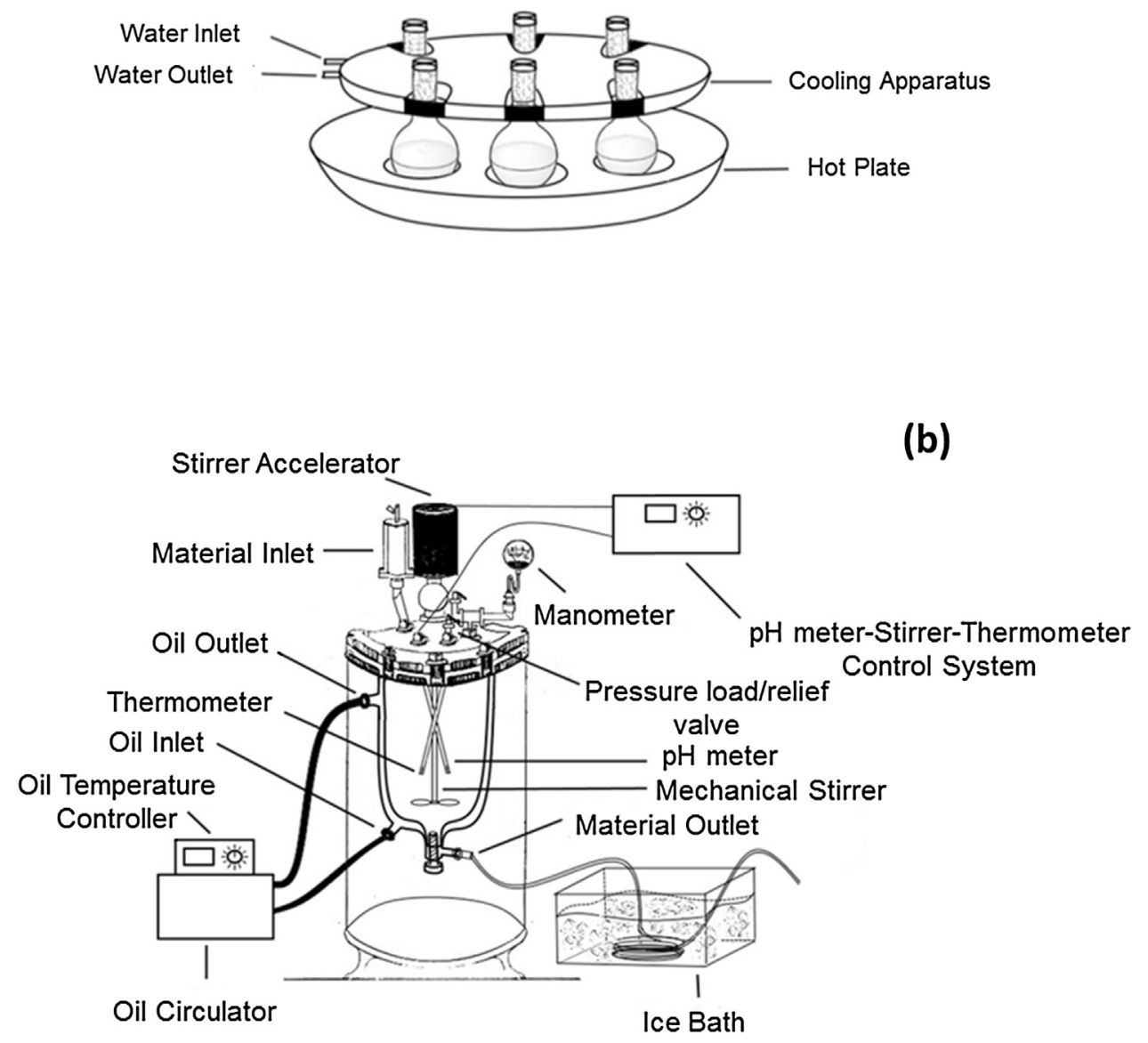

Fig. 2. Schematic view of (a) Reflux and (b) Autoclave reactor system.

confirm the efficacy of the inhibition performance of potential organic compound inhibitors.

\section{Materials and methods}

For the synthesis of artificial metal silicate deposits, two different types of apparatus were used, namely, reflux and autoclave systems. The former included a round-bottom flask heated to $90{ }^{\circ} \mathrm{C}$ under atmospheric conditions. A Radleys Carousel 6 Plus Reaction Station (Saffron Walden, UK) was used as the reflux system (Fig. 2a). A 075 miniclave (Buchiglasuster, Uster, Switzerland) was used as the autoclave reactor. This reactor had three main components: a main skeleton, a circulator device, and a monitor. The main skeleton comprised a closed container, liquid and gas inlets, a magnetic mixing motor, and temperature and $\mathrm{pH}$ probes (Fig. 2b). The closed container was made of glass and consisted of two layers. Hot silicone oil was introduced between these layers and removed by the circulator device at temperatures of up to $250{ }^{\circ} \mathrm{C}$. The magnetic mixing motor stirred the reaction solution uniformly at speeds of up to $3000 \mathrm{rpm}$. Three of the inlets/ outlets on the closed container were used for the circulation of silicone oil and one of them was used to remove the heated solution. Values of temperature (up to $100{ }^{\circ} \mathrm{C}$ ) and $\mathrm{pH}$ were measured with the probes and displayed on the monitor screen.

\subsection{Synthesis of artificial metal silicate deposits}

The precipitates were synthesized from synthetic brine, which was prepared by mixing equal volumes of solutions of $\mathrm{FeCl}_{2} \cdot 4 \mathrm{H}_{2} \mathrm{O}$ and $\mathrm{MgCl}_{2} \cdot 6 \mathrm{H}_{2} \mathrm{O}$, which were purchased from Merck (New York, USA),
$\mathrm{CaCl}_{2}$ and $\mathrm{Na}_{2} \mathrm{CO}_{3}$, which were obtained from Sigma-Aldrich (St. Louis, MO, USA), and $\mathrm{Na}_{2} \mathrm{SiO}_{3}$ (35.5 wt.\% in $\mathrm{H}_{2} \mathrm{O}$ ), which was purchased from Carl Roth (Karlsruhe, Germany). Reagent-grade Na silicate solution was diluted with distilled water $(13.2 \mathrm{mS} / \mathrm{cm})$ to yield a concentration of approximately $2 \mathrm{~g} / \mathrm{L} \mathrm{SiO}_{2}$. The initial concentrations of the artificial brine solution are given in Table 1 . Nine trials are reported in this paper. The $\mathrm{pH}$ of the reaction mixture was about 8.0 and no adjustments were made.

An aliquot of $100 \mathrm{~mL}$ synthetic brine solution was placed in the reflux system at $90^{\circ} \mathrm{C}$ and was mixed at $200 \mathrm{rpm}$. After $6 \mathrm{~h}$, the reaction mixture was left to cool slowly to room temperature. The reaction mixture consisted of solid particles in an aqueous solution, which were isolated via centrifugation, and the leftover solution was collected.

Table 1

Initial concentration of synthetic brine solutions for Reflux and Autoclave reactors.

\begin{tabular}{llllllll}
\hline \multicolumn{2}{l}{ Initial Concentrations (ppm) } & & & \multicolumn{3}{l}{ Conditions } \\
\cline { 1 - 5 } Ions & Trial & {$\left[\mathrm{Fe}^{2+}\right]$} & {$\left[\mathrm{Mg}^{2+}\right]$} & {$\left[\mathrm{Ca}^{2+}\right]$} & {$\left[\mathrm{Na}^{+}\right]$} & {$\left[\mathrm{SiO}_{2}\right]$} & \\
\hline \multirow{2}{*}{ Reflux } & 1 & 927 & 404 & 665 & 600 & 285 & \multirow{2}{*}{$90^{\circ} \mathrm{C}, 1$ bar } \\
& 2 & 927 & 404 & 1330 & 1147 & 1000 & \\
& 3 & 927 & 404 & 1330 & 1912 & 2000 & \\
Autoclave & 4 & 927 & 404 & 665 & 600 & 285 & $137.6{ }^{\circ} \mathrm{C}$, \\
& & & & & & & $3.2 \mathrm{bar}$ \\
& 5 & 927 & 404 & 1330 & 1147 & 1000 & \\
& 6 & 927 & 404 & 1330 & 1912 & 2000 & \\
7 & - & 404 & 1330 & 1912 & 2000 & \\
8 & 927 & - & 1330 & 1912 & 2000 & \\
9 & 927 & 404 & - & 1912 & 2000 & \\
\hline
\end{tabular}



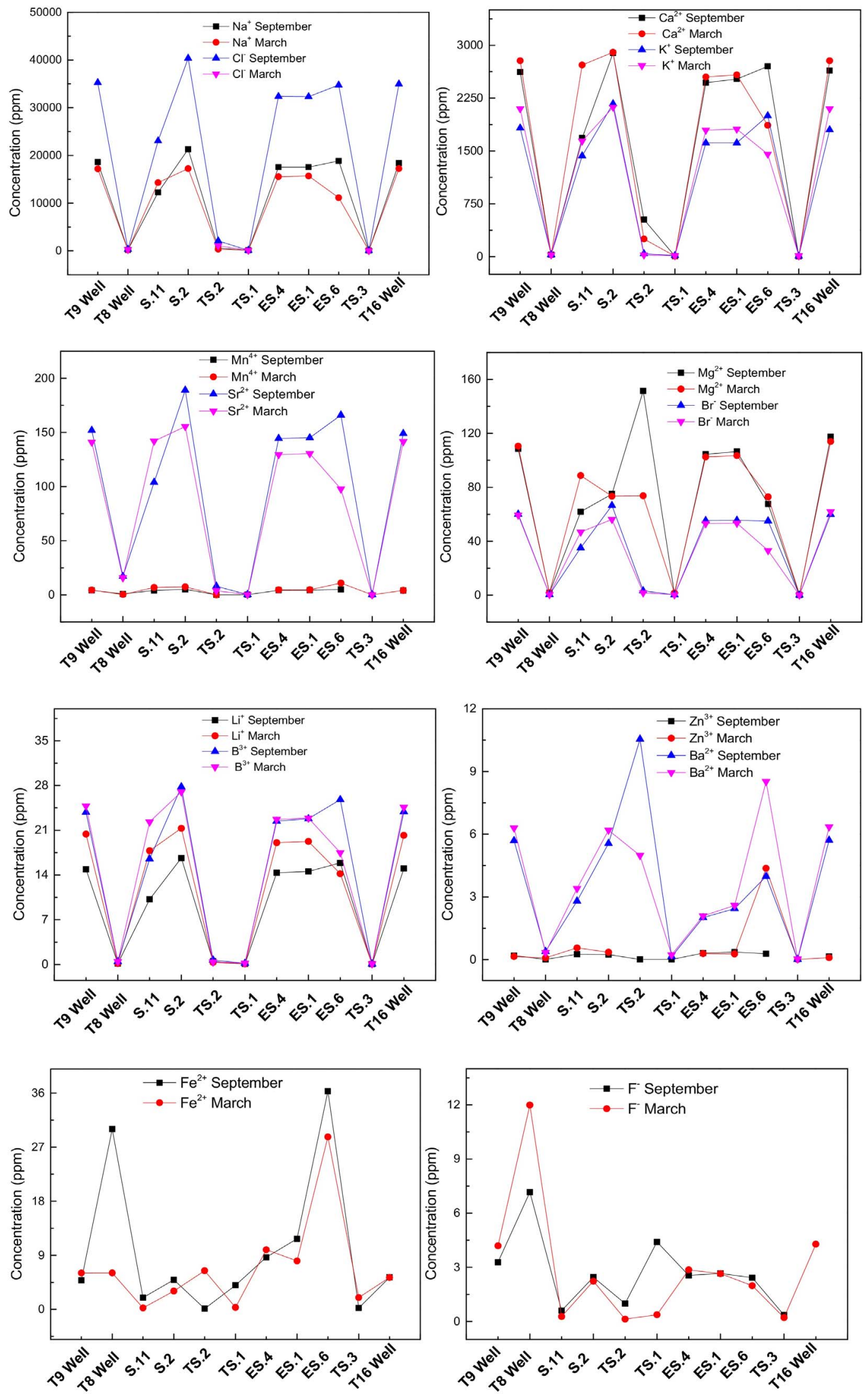

Fig. 3. Major ions and heavy metals in Tuzla Geothermal Fluid. 

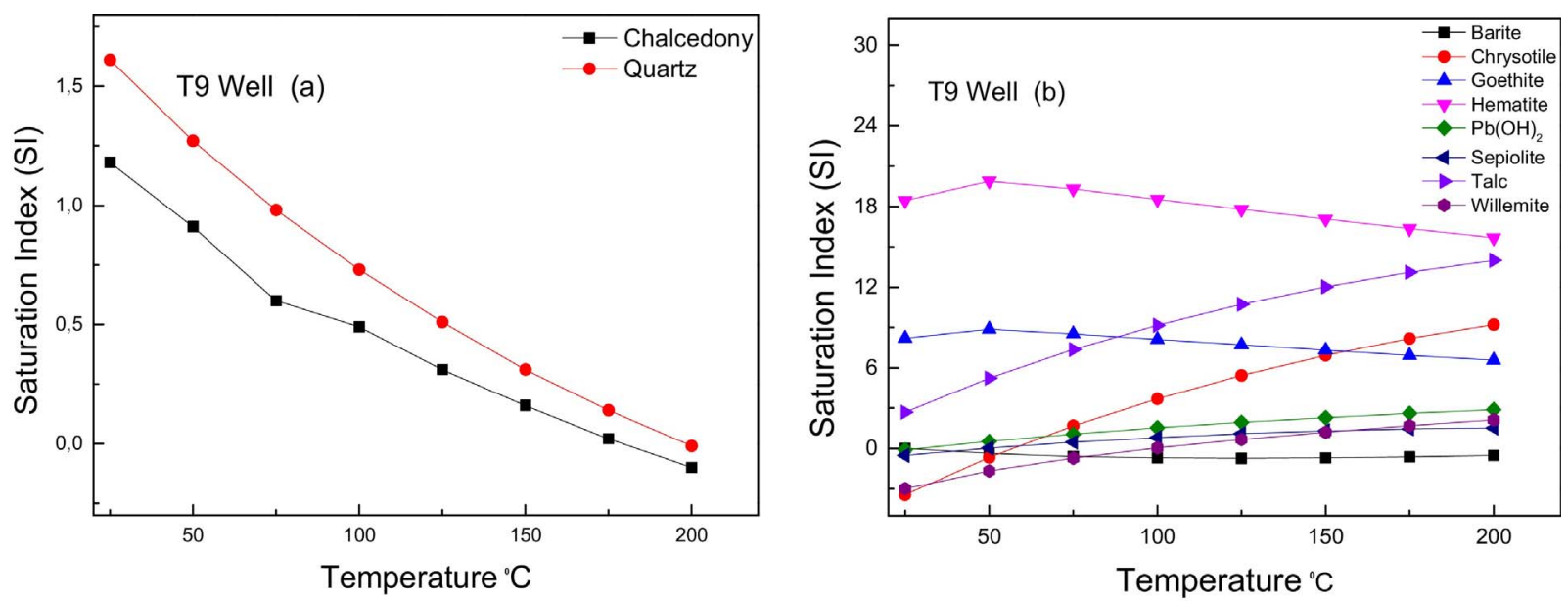

Fig. 4. Scaling potential of Tuzla Geothermal Field production wells (T9) upon boiling of aquifer fluid a) Silicate, b) Potential deposits.

The synthetic brine solution was placed in the closed container of the autoclave reactor system. Prior to the reaction, air at a pressure of 1 bar was loaded into the system. The reaction was completed after about $45 \mathrm{~min}$. The final pressure and temperature values were $3.2 \mathrm{bar}$ and $137.6{ }^{\circ} \mathrm{C}$, respectively. The reaction solution was removed with a Teflon pipe, which was placed in an ice-water bath to shock the reaction solution. This pipe is the most important part of the system, because scaling occurs in this area. After $2 \mathrm{~h}$, the solution containing the precipitate was taken and centrifuged to separate the precipitate (deposit) from the decantate. The deposit was dried in an oven at $140{ }^{\circ} \mathrm{C}$ for $4 \mathrm{~h}$. Both solid and liquid samples were subjected to characterization separately. For the decantates, spectroscopic techniques were used to determine the ion concentration. Soluble $\mathrm{SiO}_{2}$ was assayed via the silicomolybdate UV colorimetric method with a Hach DR 5000 spectrophotometer (Colorado, USA) using the 656 Silica HR program. Cations in the decantate $\left(\mathrm{Na}^{+}, \mathrm{Ca}^{2+}, \mathrm{Mg}^{2+}\right.$, and $\left.\mathrm{Fe}^{2+}\right)$ were measured via inductively coupled plasma-mass spectrometry with an Agilent 7500 ce Octopole (Santa Clara, USA) instrument. For the precipitates, the samples were powdered with a mortar and subjected to characterization using X-ray diffraction (XRD), X-ray fluorescence, scanning electron microscopy (SEM), X-ray photoelectron spectroscopy (XPS), and electron paramagnetic resonance (EPR). The crystal structure, morphology, elemental composition, binding energies, and paramagnetism of the deposits were determined using XRD (Philips X'Pert Pro, Eindhoven, The Netherlands) $\left(2 \theta=5-80^{\circ}\right.$, std.), SEM (FEI Quanta 250 FEG, Oregon, USA) (the sample was covered with gold under vacuum), XRF (Spectro iQ II, Kleve, Germany) (mass loss on fusion), XPS surface analysis (K-Alpha, Massachusetts, USA), and EPR (Adani CMS 8400, Minsk, Belarus) (20 dB), respectively.

\subsection{Effect of metal cations}

A combination of chloride salts of metal cations $\left(\mathrm{Mg}^{2+}, \mathrm{Ca}^{2+}\right.$, and $\mathrm{Fe}^{2+}$ ) that give precipitates in the presence of silicic acid and carbonate ions was tested. Nine trials were performed to investigate the features of natural deposits. To get further insight into the formation mechanism of deposits, experiments were performed in the absence of each divalent metal cation. Equal $40 \mathrm{~mL}$ volumes of solutions were mixed, made up to $200 \mathrm{~mL}$, and then reacted under the same conditions of $3.2 \mathrm{bar}$ and $137.6{ }^{\circ} \mathrm{C}$. The results for both decantates and deposits were compared with those of Trial 6, which gave the closest features to those of deposits.

\subsection{Characterization of brine}

Geothermal fluids were taken from wells (T8, T9, and T16) and springs (S-2, S-11, TS-1, TS-3, ES-1, ES-4, and ES-6) during the wet and dry seasons in the TGF. For the analyses of major ions and trace metals, $1 \mathrm{~L}$ plastic bottles were used. To prevent the formation of complexes of trace elements with oxygen, samples were filtered using $0.45 \mu \mathrm{m}$ filter paper and acidified to a $\mathrm{pH}$ of $\leq 2$ by adding $0.5 \mathrm{~N} \mathrm{HNO}_{3}$ in the field. Chemical analyses of major cations and heavy metals were carried out using inductively coupled plasma atomic emission spectrometry for $\mathrm{B}^{3+}, \mathrm{Ba}^{2+}, \mathrm{Cr}^{2+}, \mathrm{Fe}^{2+}, \mathrm{Li}^{+}, \mathrm{Pb}^{2+}$, and $\mathrm{Zn}^{2+}$, etc., whereas $\mathrm{SO}_{4}{ }^{2-}, \mathrm{Cl}^{-}$, $\mathrm{Ca}^{2+}, \mathrm{Mg}^{2+}, \mathrm{Na}^{+}$, and $\mathrm{K}^{+}$were determined by ion chromatography, and $\mathrm{HCO}_{3}{ }^{-}$concentrations were determined by titration.

\section{Results and discussion}

\subsection{Hydrogeochemical properties of geothermal fluids}

Sodium and chloride are the dominant ions in the geothermal fluids of the TGF. The reddish-black color of the geothermal brine, which has high $\mathrm{Mg}^{2+}, \mathrm{Ca}^{2+}, \mathrm{K}^{+}$, and $\mathrm{Fe}^{2+}$ contents, is attributed to the dissolution of ferromagnesian minerals present within Miocene volcanic rocks, which consist of trachyte, andesite, and trachyte-andesite (see Fig. 1). These rocks are highly altered and contain quartz, K-feldspar, biotite, amphibole, sanidine, chalcopyrite, pyrite, and hematite. The concentrations of ions such as $\mathrm{Li}^{+}, \mathrm{B}^{3+}$, and $\mathrm{Sr}^{+}$in geothermal fluids were found to be extremely high in the TGF and have been observed to reach 20, 25, and $180 \mathrm{mg} / \mathrm{L}$, respectively (Fig. 3). This is related to the presence of volcanic rocks but may also be controlled by the degassing of magma intrusions (Baba et al., 2015).

Figs. 4 and 5 show the saturation indices (SIs) of relevant hydrothermal minerals as a function of temperature for the TGF. The SIs were initially calculated using PHREEQCI computer code (Parkhurst and Appelo, 1999) at the outlet temperature and measured $\mathrm{pH}$ value. The SI is used to assess the departure of mineral saturation from equilibrium and is expressed as $\mathrm{SI}=(\log Q) / K$, where $Q$ is the reaction quotient/ activity product of the mineral dissolution reaction and $K$ is the equilibrium constant. The SIs with respect to chalcedony and quartz approached zero at $\sim 200{ }^{\circ} \mathrm{C}$ in samples from production wells T9 and T16 collected in March 2015 (Figs. 4a and 5a). There is a significant correlation between the formation of chalcedony and/or saturation of quartz and the temperature. The calculated SIs of chalcedony and quartz increased with decreases in the calculated temperature. The SIs of other saturation minerals such as chrysotile, talc, sepiolite, willemite, and $\mathrm{Pb}(\mathrm{OH})_{2}$ increased with increases in the calculated temperature (Figs. $4 \mathrm{~b}$ and $5 \mathrm{~b})$.

\subsection{Morphology and structure of the deposits}

The quantitative properties of TGF fluids and deposits have been investigated in our previous studies, in which the concentrations of ions 

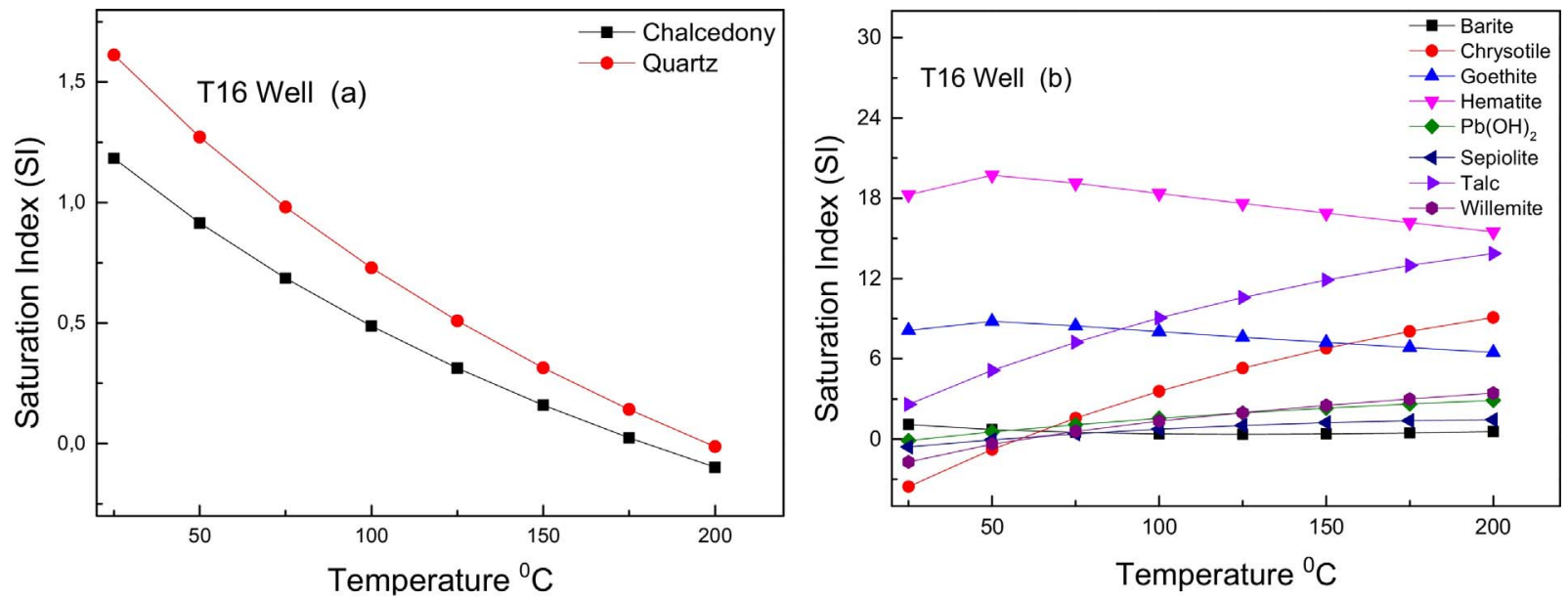

Fig. 5. Scaling potential of Tuzla Geothermal Field production wells (T16) upon boiling of aquifer fluid a) Silicate, b) potential deposits.
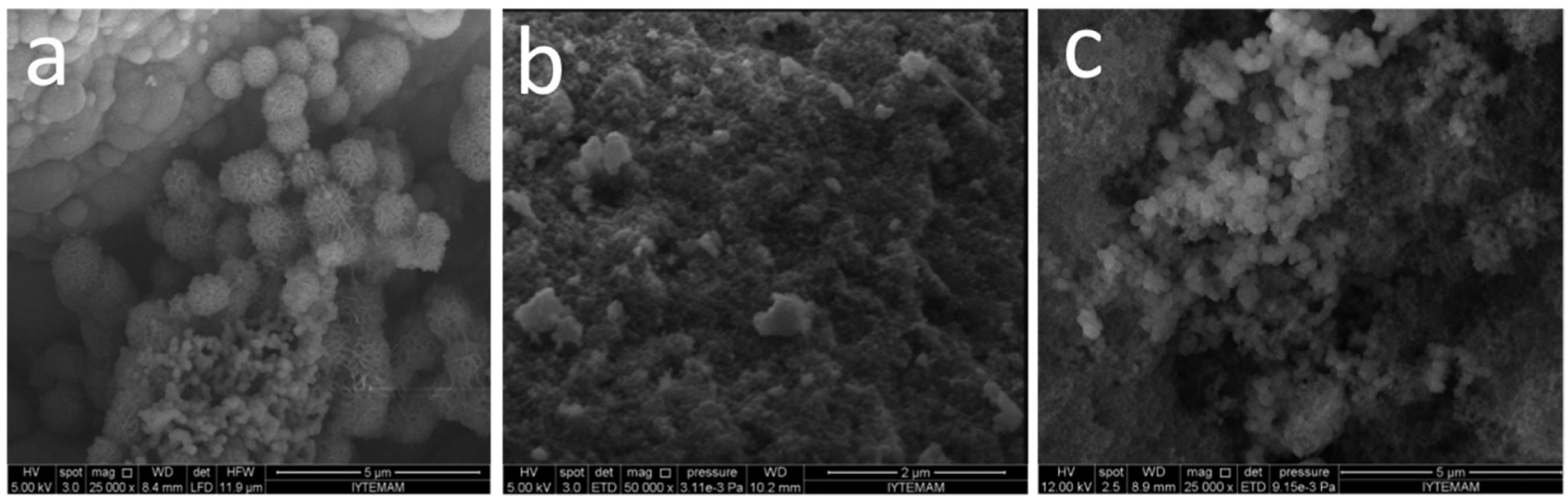

Fig. 6. SEM images of deposits obtained from a) TGF (vaporizer) $\times 25 k$, b) Reflux $\times 50 k$, and c) Autoclave $\times 25 k$.

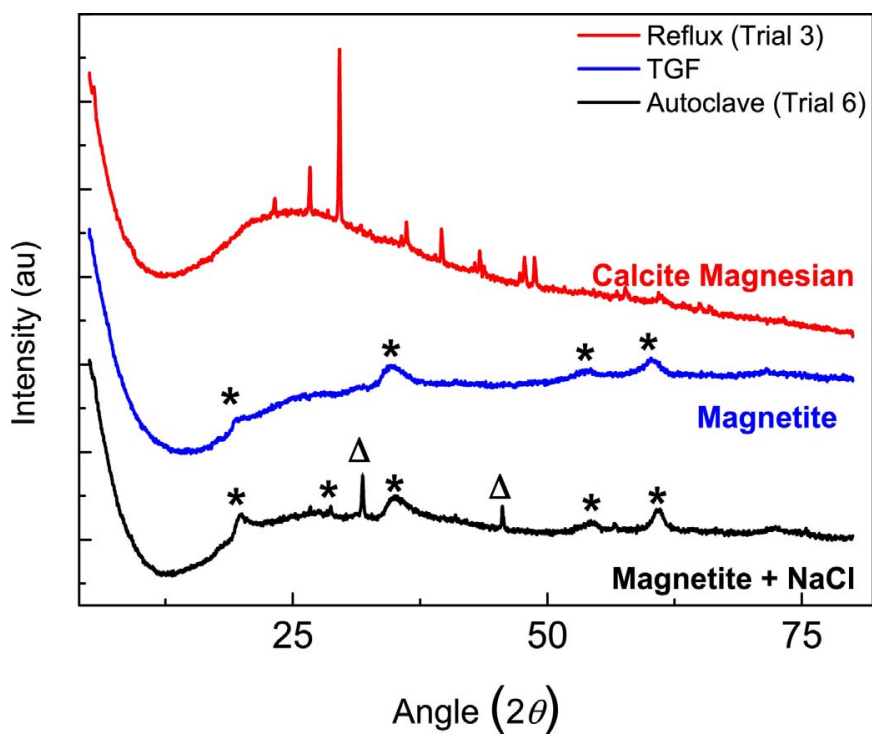

Fig. 7. XRD of deposits obtained from TGF (vaporizer), Reflux, and Autoclave (Magnetite *, $\mathrm{NaCl} \Delta$ ).

in decantates and the elemental mass compositions (\%) of TGF deposits were reported (Baba et al., 2015; Demir et al., 2014; Dogan et al., 2014). The results show that the deposit observed in the pipeline is (Fe, $\mathrm{Mg}$ ) silicate. On the other hand, the brine was found to contain a very high concentration of $\mathrm{NaCl}$, and its electrical conductivity was measured to be $100 \mathrm{mS} / \mathrm{cm}$, which is almost double that of seawater. The morphology of deposits was examined using SEM. Fig. 6 shows representative SEM micrographs of natural deposits from the TGF and synthetic deposits obtained using reflux and autoclave techniques. Natural TGF deposits are heterogeneous in nature (Fig. 6a) and contain spherical components with a size of less than $1 \mu \mathrm{m}$. This feature may be associated with the presence of amorphous silica, which is considered to be one of the main components of the deposit. The submicron size allows agglomeration into larger structures to occur such that only part of an agglomerate is observed in the field of an electron micrograph. In addition, although this may not be clearly seen in the SEM image, a controlled spherical aggregate of sharp flakes is present, as was shown in our previous study (Demir et al., 2014). This structure can be attributed to the formation of a double layer, which presumably consisted of $\mathrm{Fe}^{2+}$ and $\mathrm{Mg}^{2+}$ ions. These cations form positively charged layers separated by a distance of several angstroms with negatively charged ions, such as hydroxide, located in the intermediate region (Uan et al., 2010). The synthetic deposit prepared by refluxing exhibited a large feature in which nanosized spherical particles were hardly observed under $\times 25000$ magnification (Fig. 6b). Attempts to obtain higher-magnification images were unsuccessful owing to charging of the specimen. The reason for the formation of such a large agglomerate could be the low temperature employed during the synthesis of the deposit. On the other hand, the deposit prepared by autoclaving displayed a spherical morphology (Fig. 6c) that was similar in size and shape to that found in the natural deposit.

Fig. 7 presents the XRD patterns obtained from the three deposits. The diffraction patterns of all three samples suggest the presence of an amorphous material, which is indicated by the broad background. The reflections present within this amorphous background show the presence of $\mathrm{Fe}_{3} \mathrm{O}_{4}$ (magnetite [FeO-Fe${ }_{2} \mathrm{O}_{3}$ ], ICSD collection code 082446) 
Table 2

Mass percent composition of deposits obtained from Reflux and Autoclave. TGF results are based on our previous study (Dogan et al., 2014).

\begin{tabular}{llllll}
\hline System & $\mathrm{Fe}$ & $\mathrm{Mg}$ & $\mathrm{Ca}$ & $\mathrm{Na}$ & $\mathrm{SiO}_{2}$ \\
\hline Reflux (Trial 3) & 13 & 3 & 7 & 4 & 51 \\
Autoclave (Trial 6) & $16 \pm 2$ & $4 \pm 1$ & $3 \pm 1$ & $3 \pm 2$ & $50 \pm 3$ \\
Natural & 17 & 4 & 2 & 1 & 38 \\
\hline
\end{tabular}

in the natural (TGF) and autoclave deposits (Trial 6). The pattern of the autoclave deposit also shows the presence of $\mathrm{NaCl}$ (halite, ICSD collection code 041411 ) crystals. The pattern of the deposit obtained by refluxing (Trials 1, 2, and 3) indicates the presence of calcite magnesian mineral (ICSD collection code 040108). Those deposits are beyond the scope of this study. On the basis of the results obtained for the morphology and crystal structure, it can be concluded that the precipitates obtained from the autoclave reactor (in particular Trial 6) have similar features to the deposit obtained from the vaporizer of the TGPP.

\subsection{Spectroscopic characterization of the deposits}

The chemical composition of the artificial and naturally formed deposits is reported in Table 2, which shows that the materials consist of a mixture of $\mathrm{Si}, \mathrm{Fe}, \mathrm{Mg}, \mathrm{Na}$, and $\mathrm{Ca}$. The samples were evaluated using spectroscopic analytical methods to obtain an insight into their structural formation.

EPR spectroscopy is one of the techniques employed in this study and represents a powerful method of indicating the presence of paramagnetic transition metal ions (Akdogan et al., 2008). The presence of iron species in the precipitates enables EPR to be used for the appropriate measurements (Weckhuysen et al., 2004). In general, $\mathrm{Fe}^{3+}$ ions $\left(d^{5}, S=5 / 2\right)$ are in a high-spin electronic configuration in the presence of weak field ligands such as oxygen, water, or hydroxyl ligands (Goldfarb et al., 1994). Furthermore, according to their chemical environment, $\mathrm{Fe}^{3+}$ species generate EPR signals with different $g$ values. The usual X-band EPR signals of $\mathrm{Fe}^{3+}$ are observed at $g \approx 4.2-4.3, g \approx 2.2$, and $g \approx 2.0$ (Kim et al., 2010). Although alternative interpretations exist in the literature for the assignments of these EPR signals, the commonly accepted assignments are as follows: framework iron in a tetrahedral environment and iron oxide species and iron ions coupled by exchange interactions in a distorted octahedral environment, respectively (Srinivasulu et al., 2013; Weckhuysen et al., 2004).

Fig. 8a shows the X-band EPR spectra of TGF and artificial deposits (Trial 5 and Trial 7, latter deposit containing no iron), which were recorded at room temperature. The spectra of the TGF deposit and the artificial precipitate from Trial 5 were normalized to the same iron content. The same amount of precipitate without iron (Trial 7), which was also measured as a reference sample, displayed two weak signals at $g=4.2$ and $g=2.0$ owing to trace amounts of iron, whereas the remaining components of the precipitates did not contribute to the EPR spectrum. The TGF and Trial 5 deposits exhibited two signals: an intense signal at $g=2.2$ and a weak signal at $g \approx 4.2$. The intense signal observed at $g=2.2$ shows the formation of iron oxide clusters in both TGF and artificial (Trial 5) deposits. The weak signal at $g \approx 4.2$ indicates the presence of substituted $\mathrm{Fe}^{3+}$ ions in the framework of both the TGF deposit and the artificial (Trial 5) precipitate.

Ferrous chloride can be oxidized to ferric chloride in the reaction medium (air and water vapor). Nevertheless, the results for both the TGF deposits and the synthetic precipitates indicate the coexistence of ferric and ferrous ions. These results suggest that the presence of air in the reaction medium was not able to oxidize the entire ferrous ion content. Note that the presence of ferric ions gives rise to magnetic behavior. Both the natural deposit and the autoclave precipitate displayed magnetic behavior, which also confirms the presence of both ions and rules out the complete oxidation of ferrous ions to ferric ions.

The EPR spectra recorded for the other precipitates (Trials 1, 2, 3, 4, and 6 ) show the appearance of a new broad signal at $g \approx 2.0$, whereas the signals at $g=4.2$ and $g \approx 2.2$, which were observed for the natural and artificial Trial 5 samples, have disappeared (Fig. 8b). In the literature, intense EPR signals at $g \approx 2.0$ have been attributed to the formation of iron clusters by spin-spin interactions and to iron ions coupled by exchange interactions in a distorted octahedral environment (Muralidhara et al., 2010). Although the $g$ values of the TGF deposit are similar to those of the artificial Trial 5 precipitate, they are different from the $g$ values of the other artificial precipitates (Trials 1, 2, 3, 4, and 6) (Fig. 8b). These results provide an understanding of the chemical environment and structure of iron species in the artificial precipitates based on their method of preparation and their initial compositions.

XPS was employed to investigate the compositions of the samples. The binding energies of atoms give information about the structure of materials. Fig. 9a shows the XPS survey spectra of the natural (TGF) deposit and an artificial precipitate obtained using the autoclave system (Trial 6). Both spectra show an intense oxygen (O 1s) signal and weaker signals of Mg 1s, Fe 2p, Fe 3p, Si 2p, Ca 2p, and Na 1s. The peak binding energies for each of these signals are summarized in Table 3 . The table also contains reference data for the binding energies of metals and oxygen obtained from the literature. The spectra (Fig. 9b) show that the $\mathrm{O} 1 \mathrm{~s}$ binding energies of the TGF deposit and autoclave precipitate were located at 532.0 and $532.7 \mathrm{eV}$, respectively (see also Table 3). Jensen et al. (2013) attributed a signal at $532.8 \mathrm{eV}$ to what they referred to as lattice oxygens in $\mathrm{SiO}_{2}$, where all four oxygen atoms are linked to silicon atoms (also referred to as bridging oxygens). When compared with the reference binding energy of $532.8 \mathrm{eV}$ found by Jensen et al., the lower value found for the TGF deposit can be attributed to the
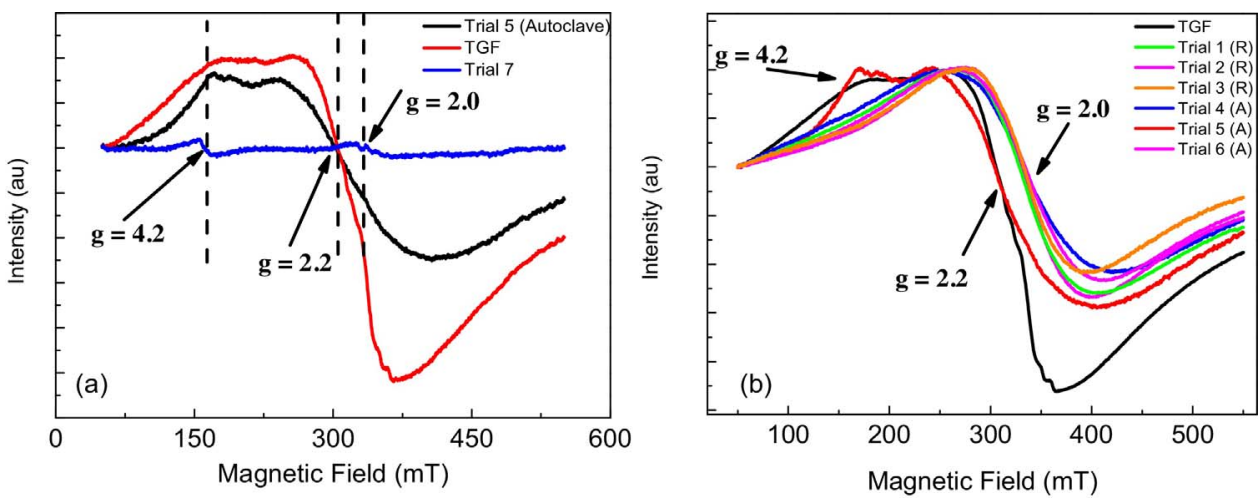

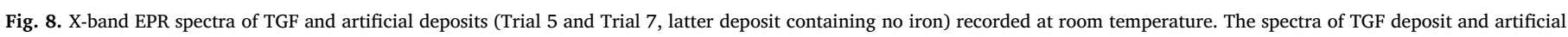

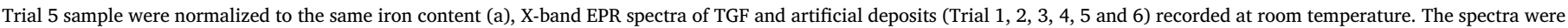
normalized to their maxima (b). 

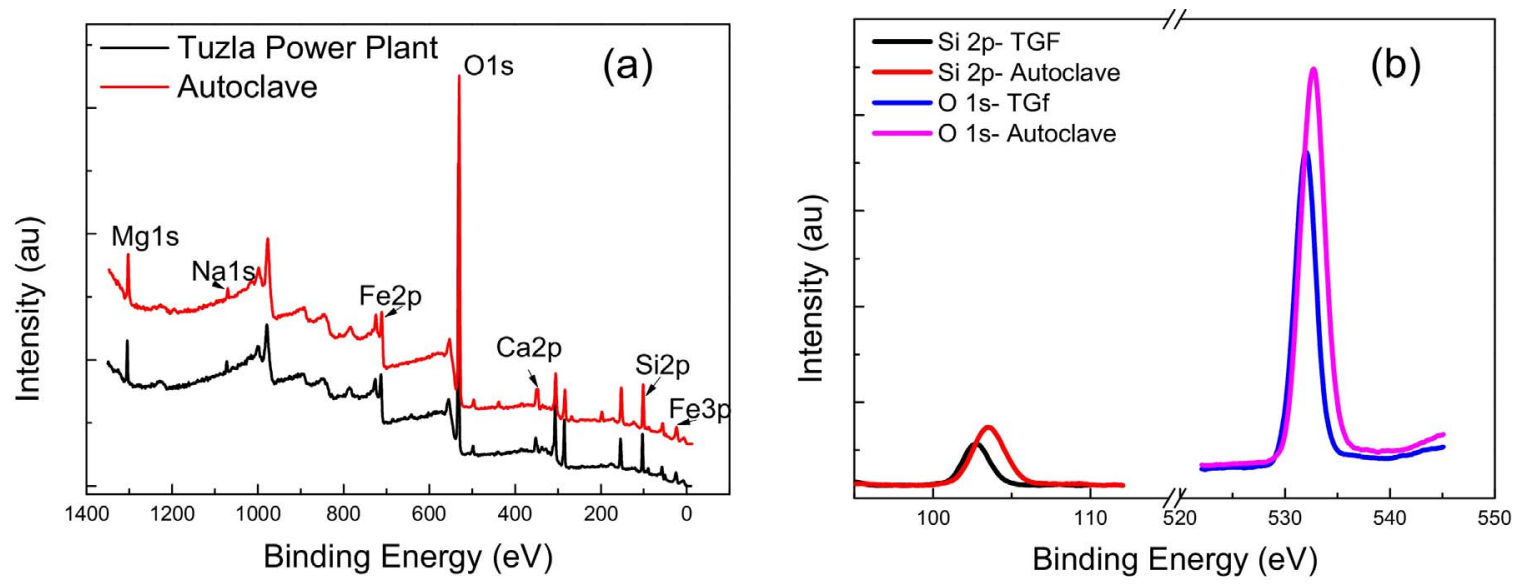

Fig. 9. XPS survey spectra of the natural deposit and precipitate obtained from Autoclave system (a) overall, (b) Si $2 \mathrm{p}$ and $\mathrm{O} 1 \mathrm{~s}$ atoms binding energy.

Table 3

Binding energies, in eV, for TGF and Autoclave samples, and reference compounds of identified metal salts.

\begin{tabular}{|c|c|c|c|}
\hline Binding Atom & TGF & Autoclave (Trial 6) & Referance Compounds \\
\hline O $1 \mathrm{~s}$ & 532.0 & 532.7 & $532.8\left(\mathrm{SiO}_{2}\right)$ (Jensen et al., 2013) \\
\hline Si $2 p$ & 102.7 & 103.5 & $103.5\left(\mathrm{SiO}_{2}\right)$ (Jensen et al., 2013) \\
\hline $\mathrm{Na} 1 \mathrm{~s}$ & 1072.5 & 1072.9 & $1071.5\left(\mathrm{Na}_{2} \mathrm{O}\right)$ (Mekki et al., 1996) \\
\hline Fe $2 p$ & 712.1 & 712.8 & $711.0\left(\mathrm{Fe}_{3} \mathrm{O}_{4}\right)$ (Yamashita and Hayes, 2008) \\
\hline Fe $3 p$ & 56.6 & 57.8 & $55.6\left(\mathrm{Fe}_{2} \mathrm{O}_{3}\right)$ (Yamashita and Hayes, 2008) \\
\hline $\operatorname{Mg} 1 \mathrm{~s}$ & 1304.2 & 1304.6 & 1304.5 (MgO) (http://xpssimplified.com/elements/magnesium.php. 2017.01.28) \\
\hline $\mathrm{Ca} 2 \mathrm{p}$ & 351.7 & 348.6 & $347.2\left(\mathrm{CaCO}_{3}\right)$ (http://xpssimplified.com/elements/calcium.php. 2017.01.28) \\
\hline
\end{tabular}

presence of non-linked oxygens (also referred to as non-bridging oxygens) in the $\mathrm{SiO}_{2}$ framework (Mekki et al., 1996). The charge balance of the dangling bonds from the non-bridging oxygens is satisfied by the presence of metal cations (Mekki et al., 1996). The results also show that the $\mathrm{O} 1 \mathrm{~s}$ binding energies of the autoclave precipitates exhibit much smaller differences, which suggests that these samples have lower amounts of non-bridging oxygens, i.e., they have more Si-O linkages. This finding may be associated with the absence of metal salts in the silicate networks of the autoclave precipitates in comparison with the TGF deposit. The reference binding energy of Si $2 p$ (Fig. 9b) at $103.5 \mathrm{eV}$ is attributed to silicon atoms linked to oxygen atoms in the $\mathrm{SiO}_{2}$ tetrahedra (Mekki et al., 1996). In relation to the linked silicon atoms, a lower binding energy of $102.7 \mathrm{eV}$ was measured for the TGF deposit, whereas the binding energy measured for the autoclave deposits was $103.5 \mathrm{eV}$, which was similar to the reference value. The lower binding energy in the TGF sample is explained by the relative lack of $\mathrm{Si}-\mathrm{O}$ linkages in the $\mathrm{SiO}_{2}$ tetrahedra, where the metal ions have penetrated into the silica framework (Mekki et al., 1996). The kinetics of precipitate formation is very rapid in an autoclave in comparison to the formation of natural deposits in the TGF. Not surprisingly, the kinetics of deposit formation is very rapid in geothermal fields. Because the brine is pumped to the ground surface rapidly, the atoms do not have enough time to rearrange and form linkages, as they would in an equilibrium process. The lower binding energy in the TGF deposits is also consistent with the explanation of the difference in the $\mathrm{O} 1 \mathrm{~s}$ binding energies between the two deposits. The TGF and autoclave deposits displayed $\mathrm{Na} 1 \mathrm{~s}$ signals at 1072.5 and $1072.9 \mathrm{eV}$, respectively. Normally, the $\mathrm{Na} 1 \mathrm{~s}$ binding energy is $1071.5 \mathrm{eV}$ (Mekki et al., 1996). The increase in the binding energy of $\mathrm{Na}$ atoms may be related to the binding of the atoms to other ionic atoms and hence to the presence of $\mathrm{NaCl}$ crystals. Similarly, the increase found in the binding energy of Ca $2 p$ with respect to its reference value (see Table 3 ) may be associated with the formation of a crystalline calcium salt in both the TGF and autoclave deposits. The relatively higher binding energy associated with the TGF sample suggests that the concentration of such salts was higher in comparison with that in the autoclave sample. The similarity in the binding energies of $\mathrm{Mg} 1 \mathrm{~s}$ suggests that the structural differences were slight, in particular between the TGF and autoclave deposits. The reference binding energies of $\mathrm{Fe} 2 \mathrm{p}$ and $\mathrm{Fe} 3 \mathrm{p}$ have been measured to be 711.0 and $55.6 \mathrm{eV}$, respectively. These reference values correspond to hematite $\left(\mathrm{Fe}_{2} \mathrm{O}_{3}, \mathrm{Fe} 2 \mathrm{p}\right)$ and magnetite $\left(\mathrm{Fe}_{3} \mathrm{O}_{4}, \mathrm{Fe} 3 \mathrm{p}\right)$ (Yamashita, 2008). The TGF and autoclave deposits displayed larger binding energy values for both iron compounds, as shown in Table 3. The results of XRD and EPR studies suggest that iron exists both in the form of magnetite crystals and dissolved as iron clusters within the amorphous silicate network. The XPS binding energy data for iron atoms do not appear to fully match those of magnetite crystals or show clear indications of an amorphous structure, which suggests that the

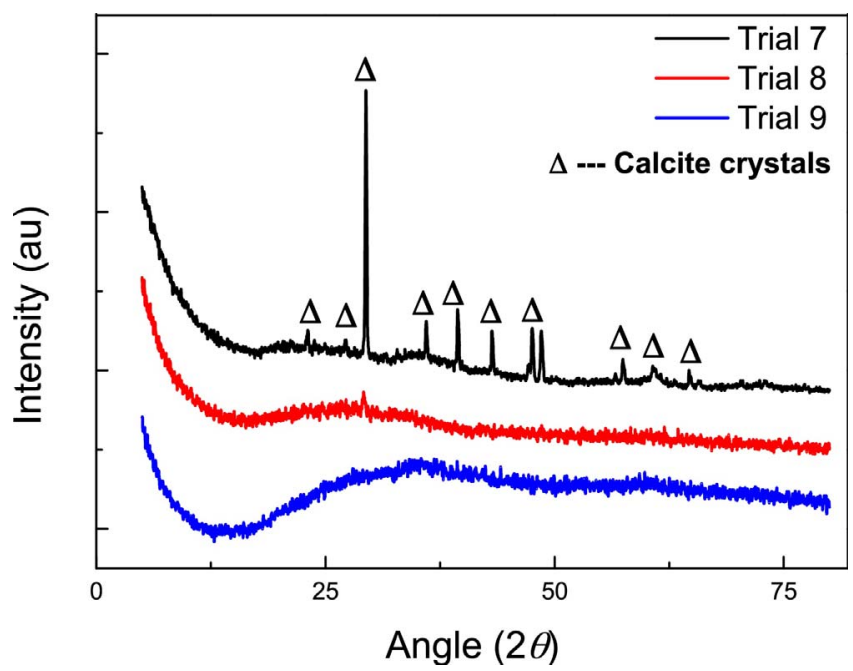

Fig. 10. XRD pattern of the deposits obtained from Na Silicate in the presence of various salts given in Table 1 Trial $7\left(\mathrm{Na}^{+}, \mathrm{Ca}^{2+}, \mathrm{Mg}^{2+}\right.$ and $\left.\mathrm{SiO}_{2}\right)$, Trial $8\left(\mathrm{Na}^{+}, \mathrm{Ca}^{2+}, \mathrm{Fe}^{2+}\right.$ and $\left.\mathrm{SiO}_{2}\right)$ and Trial $9\left(\mathrm{Na}^{+}, \mathrm{Mg}^{2+}, \mathrm{Fe}^{2+}\right.$ and $\left.\mathrm{SiO}_{2}\right)$. 
XPS analysis was not able to clearly differentiate the different structures adopted by iron in the deposit.

To get an insight into the association of metal cations with silicates, the same reaction (under the conditions used in Trial 6) was performed in the absence of each cation $\left(\mathrm{Fe}^{2+}, \mathrm{Mg}^{2+}\right.$, and $\mathrm{Ca}^{2+}$ in Trial 7, 8, and 9 , respectively) (Table 1 ). In the presence of $2 \mathrm{~g} / \mathrm{L} \mathrm{SiO}_{2}$, each cation was removed from the composition consecutively and the resulting deposit was examined by XRD. Fig. 10 presents the XRD patterns of the samples obtained from these reactions. Trials 8 and 9 (in the absence of calcium and magnesium, respectively) provided amorphous patterns, whereas the absence of iron yielded a crystalline pattern (Trial 7) that matched that of the calcite form of $\mathrm{CaCO}_{3}$ for a product in the form of a soft, white powder. This result highlights the importance of the presence of iron in the chemical composition of the deposit and suggests that iron has a stronger tendency to become incorporated in the silicate structure in comparison to $\mathrm{Ca}^{2+}$ and $\mathrm{Mg}^{2+}$, which prevents the formation of $\mathrm{CaCO}_{3}$. This result is corroborated by the EPR measurements.

\section{Conclusions}

Tuzla geothermal brine is hypersaline and causes the formation of deposits with various chemical compositions. The chemical compositions of these deposits, for instance, quartz and chalcedony, were estimated from SIs using PHREEQCI computer code. The results were consistent with those for natural deposits observed in the field that have been indexed as magnetite in an amorphous silicate network. A reflux system, which is commonly employed in many chemistry laboratories, was used for the synthesis of artificial deposits. An alternative strategy was developed for the synthesis of artificial deposits using an autoclave reactor, in which conditions in the field can be replicated. Examinations of the morphology and structure of the deposits (both naturally formed and artificially generated) are in agreement with the estimates made using the computer code. In contrast to those produced by the reflux system, the artificially generated deposits obtained using the autoclave reactor were found to be similar to the naturally formed deposits in terms of their internal structure and elemental composition. The microscopic and spectroscopic analytical techniques used in the study were shown to be effective in determining the nature of the natural and artificially formed samples. Analysis by electron microscopy revealed that the morphology of the natural deposits and samples formed in the autoclave mainly comprised clusters of nanoscale particles that had a spherical geometry. Via XRD, EPR, and XPS examinations, the structures of these formations were found to contain both crystalline and amorphous regions. The crystalline region was identified as consisting of magnetite $\left(\mathrm{Fe}_{3} \mathrm{O}_{4}\right)$ and salts of sodium, calcium, and magnesium. The amorphous portion was identified as a silicate structure modified by sodium, iron, and calcium. The methodology and findings used in this study show that this strategy can be employed in the laboratory to test the performance of potential inhibitors. Furthermore, the structural and morphological information obtained from the precipitates can be utilized in designing efficient inhibitors of metal silicate deposits.

\section{Funding sources}

This research is funded by The Scientific and Technological Research Council of Turkey (TUBITAK) with a project number $114 \mathrm{Z} 940$.

\section{Acknowledgments}

The authors acknowledge The Centers of Materials Research and of Environmental Research at Izmir Inst. Technol. for assistance in all measurements. The authors are grateful to Tuzla-GPP for the supplying the natural deposits and brine.

\section{References}

Akdogan, Y., Vogt, C., Bauer, M., Bertagnolli, H., Giurgiu, L., Roduner, E., 2008. Platinum species in the pores of $\mathrm{NaX}, \mathrm{NaY}$ and NaA zeolites studied using EPR, XAS and FTIR spectroscopies. Phys. Chem. Chem. Phys. 10, 2952-2963.

Baba, A., Demir, M.M., Koç, G.A., Tuğcu, C., 2015. Hydrogeological properties of hypersaline geothermal brine and application of inhibiting siliceous scale via $\mathrm{pH}$ modification. Geothermics 53, 406-412.

Brown, K., 2011. Thermodynamics and kinetics of silica scaling. International Workshop on Mineral Scaling.

Chen, C.-T.A., Marshall, W.L., 1982. Amorphous silica solubilities IV. Behavior in pure water and aqueous sodium chloride, sodium sulfate, magnesium chloride, and magnesium sulfate solutions up to $35^{\circ} \mathrm{C}$. Geochim. Cosmochim. Acta 46, 279-287.

Demadis, K.D., Neofotistou, E., 2004. Inhibition and growth control of colloidal silica: designed chemical approaches. Mater. Perform. 43, 38-42.

Demadis, K.D., Mavredaki, E., Stathoulopoulou, A., Neofotistou, E., Mantzaridis, C., 2007. Industrial water systems: problems, challenges and solutions for the process industries. Desalination 213, 38-46.

Demadis, K.D., Ketsetzi, A., Sarigiannidou, E., 2012. Catalytic effect of magnesium ions on silicic acid polycondensation and inhibition strategies based on chelation. Ind. Eng. Chem. Res. 51, 9032-9040.

Demir, M.M., Baba, A., Atilla, V., Inanl1, M., 2014. Types of the scaling in hyper saline geothermal system in northwest Turkey. Geothermics 50, 1-9.

Dogan, I., Demir, M.M., Baba, A., Baba, A., Bundschuh, D., Chandrasekharam, D., 2014 Scaling problem of the geothermal system in Turkey. Geotherm. Syst. Energy Resour. Turkey Greece 225-234.

Ehrlich, H., Demadis, K.D., Pokrovsky, O.S., Koutsoukos, P.G., 2010. Modern wievs on desilicification: biosilica and abiotic silica dissolution in natural and artificial environments. Chem. Rev. 110, 4656-4689.

Gallup, D.L., Sugiaman, F., Capuno, V., Manceau, A., 2003. Laboratory investigation of silica removal from geothermal brines to control silica scaling and produce usable silicates. Appl. Geochem. 18, 1597-1612.

Gallup, D.L., 1997. Aluminum silicate scale formation and inhibition: scale characterization and laboratory experiments. Geothermics 26, 483-499.

Gallup, D.L., 1998. Aluminum silicate scale formation and inhibition (2): scale solubilities and laboratory and field inhibition tests. Geothermics 27, 485-501.

Gallup, D.L., 2002. Investigations of organic inhibitors for silica scale control in geothermal brines. Geothermics 31, 415-430.

Ghouil, B., Harabi, A., Bouzerara, F., Boudaira, B., Guechi, A., Demir, M.M., Figoli, A., 2015. Development and characterization of tubular composite ceramic membranes using natural alumino-silicates for microfiltration applications. Mater. Charact. 103, 18-27.

Goldfarb, D., Bernardo, M., Strohmaier, K., Vaughan, D., Thomann, H., 1994. Characterization of iron in zeolites by X-band and Q-band ESR, pulsed ESR, and UVvisible spectroscopies. J. Am. Chem. Soc. 116, 6344-6353.

Icopini, G.A., Brantley, S.L., Heaney, P.J., 2005. Kinetics of silica oligomerization and nanocolloid formation as a function of $\mathrm{pH}$ and ionic strength at $25^{\circ} \mathrm{C}$. Geochim. Cosmochim. Acta 69, 293-303.

Jensen, D.S., Kanyal, S.S., Madaan, N., Vail, M.A., Dadson, A.E., Engelhard, M.H., Linford, M.R., 2013. Silicon (100)/ $/ \mathrm{SiO}_{2}$ by XPS. Surf. Sci. Spectra 20, 36-42.

Kim, M.-Y., Lee, K.W., Park, J.-H., Shin, C.-H., Lee, J., Seo, G., 2010. Catalytic decomposition of nitrous oxide over Fe-BEA zeolites: essential components of iron active sites. Korean J. Chem. Eng. 27, 76-82.

Mekki, A., Holland, D., McConville, C., Salim, M., 1996. An XPS study of iron sodium silicate glass surfaces. J. Non-Cryst. Solids 208, 267-276.

Muralidhara, R., Kesavulu, C., Rao, J., Anavekar, R., Chakradhar, R., 2010. EPR and optical absorption studies of $\mathrm{Fe}^{3+}$ ions in sodium borophosphate glasses. J. Phys. Chem. Solids 71, 1651-1655.

Parkhurst, D.L., Appelo, C., 1999. User's Guide to PHREEQC (Version 2): A Computer Program for Speciation, Batch-Reaction, One-Dimensional Transport, and Inverse Geochemical Calculations .

Saishu, H., Okamoto, A., Tsuchiya, N., 2013. The effect of Al and Na on the precipitation rate of silica minerals: hydrothermal flow-through experiments at $430{ }^{\circ} \mathrm{C}$ and 31 MPa. Procedia Earth Planet. Sci. 7, 762-765.

Srinivasulu, K., Omkaram, I., Obeid, H., Kumar, A.S., Rao, J.L., 2013. Use of $\mathrm{Fe}^{3+}$ ion probe to study the structural coordination in sodium-lead borophosphate glasses by utilizing electron magnetic resonance and optical spectroscopy. J. Alloys Compd. 546, 208-215.

Uan, J.-Y., Lin, J.-K., Tung, Y.-S., 2010. Direct growth of oriented Mg-Al layered double hydroxide film on $\mathrm{Mg}$ alloy in aqueous $\mathrm{HCO}_{3}{ }^{-} / \mathrm{CO}_{3}{ }^{2-}$ solution. J. Mater. Chem. 20 761-766.

Weckhuysen, B.M., 2006. Report on Geothermal Development Survey in the CanakkaleTuzla Field. West Japan Engineering Consultants, Inc., Turkey.

Weckhuysen, B.M., Heidler, R., Schoonheydt, R.A., 2004. Electron spin resonance spectroscopy. Characterization I. Springerpp. 295-335.

Yamashita, T., Hayes, P., 2008. Analysis of XPS spectra of $\mathrm{Fe}^{2+}$ and $\mathrm{Fe}^{3+}$ ions in oxide materials. Appl. Surf. Sci. 254, 2441-2449.

\section{Further reading}

http://xpssimplified.com/elements/calcium.php. Last accessed January 2017. http://xpssimplified.com/elements/magnesium.php. Last accessed January 2017. 